\title{
Laboreal
}

Volume $1 \mathbf{N}^{\circ} 1$ | 2005

Varia

Labirintos do Trabalho : interrogações e olhares sobre o trabalho vivo. Marcelo Figueiredo, Milton Athayde, Jussara Brito e Denise Alvarez (orgs.)

\section{Cláudia Osório}

\author{
(2) OpenEdition \\ Journals \\ Edição electrónica \\ URL: http://journals.openedition.org/laboreal/14261 \\ DOI: 10.4000/laboreal. 14261 \\ ISSN: 1646-5237 \\ Editora \\ Universidade do Porto \\ Refêrencia eletrónica \\ Cláudia Osório, « Labirintos do Trabalho : interrogações e olhares sobre o trabalho vivo. Marcelo \\ Figueiredo, Milton Athayde, Jussara Brito e Denise Alvarez (orgs.) », Laboreal [Online], Volume $1 \mathrm{~N}^{0} 1$ | \\ 2005, posto online no dia 01 dezembro 2005, consultado o 24 setembro 2020. URL : http:// \\ journals.openedition.org/laboreal/14261 ; DOI : https://doi.org/10.4000/laboreal.14261
}

Este documento foi criado de forma automática no dia 24 setembro 2020.

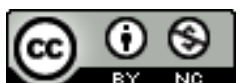

Laboreal está licenciado com uma Licença Creative Commons - Atribuição-NãoComercial 4.0 Internacional. 


\title{
Labirintos do Trabalho : interrogações e olhares sobre o trabalho vivo. Marcelo Figueiredo, Milton Athayde, Jussara Brito e Denise Alvarez (orgs.)
}

\author{
Cláudia Osório
}

1 O título deste livro dá ao interessado no tema do trabalho, desde o primeiro momento, a indicação do tom que irá aí encontrar, bem como da concepção que traz do que seja o trabalho humano : processo permanente de invenção e re-invenção da vida. Organizado num fio que se tece nas experiências e encontros de pesquisadores que tomam a atividade como um conceito que permite navegar pelos tais labirintos mencionados no título, dá um lugar privilegiado às produções disparadas pela e na proposta da ergologia, cujo autor mais proeminente

2 - Yves Schwartz nos premia com o primeiro capitulo desta obra coletiva. A proposta, tal como a apresentam Marcelo Figueiredo e seus companheiros, é produzir diálogos e polifonia, o que é plenamente alcançado, de modo totalmente fiel à visão ética e estética da própria ergologia. A abordagem ergológica, como diz Edith Seligmann-Silva já na "orelha" do livro, pressupõe o trânsito entre diversos saberes sobre o trabalho, incluindo-se aí tanto o diálogo e as intercessões entre as várias disciplinas científicas, quanto entre estas e os saberes construídos pelos trabalhadores em seu cotidiano. Entre os autores encontram-se pesquisadores de diversas linhagens, graduados em psicologia, engenharia, línguas, filosofia, e não sei que outras disciplinas mais, que se encontram numa proposta verdadeiramente pluridisciplinar e, eu diria, transdisciplinar. Podemos lê-lo buscando encontros com temas atuais, que permitem diversas alianças entre leitores e autores.

3 Antes de prosseguir, desejo esclarecer algo acerca das condições de produção desta resenha, desculpando-me pelo espaço desigual dedicado aos comentários de suas várias 
partes constitutivas. Não se trata em absoluto de considerar um autor ou artigo mais importante ou interessante que outros, mas de uma leitura marcada por uma experiência em saúde do trabalhador, inserida no contexto da prática docente na área da psicologia do trabalho.

Neste livro, diversos artigos podem ser destacados por sua intercessão com o campo da saúde do trabalhador. Podem ser lidos num fio temático em que se destaca a abertura de caminhos de intervenção, no sentido de dar potência à vida, ou à saúde no sentido que Canguilhem dá a este conceito.

Logo no segundo capítulo, o artigo de Nouroudine, com sua crítica ao conceito de risco, tradicionalmente adotado pelas propostas de prevenção de acidentes e doenças relacionadas ao trabalho, propõe indiretamente uma crítica a tudo que perpassa as ações de vigilância em saúde do trabalhador, a elaboração de mapas de risco, os programas de saúde ocupacional e outros temas que hoje estão presentes nas políticas e normas legais de saúde e segurança no trabalho em nosso país. Segundo o raciocínio desenvolvido pelo autor, as infrações ao prescrito não devem ser consideradas como índice de perturbação, ou como um correr riscos desconsiderados, mas como a busca de "conciliar saúde e eficácia nas situações de trabalho".

6 Este mesmo artigo chama também ao debate dos psicólogos do trabalho e suas formulações acerca das "resistências à mudança". Para Nouroudine, estas devem ser pensadas pela via proposta por Canguilhem, de permanente diálogo entre indivíduo e meio, "a relação do homem com a vida é o caldeirão de problemas a serem tratados" e soluções sempre provisórias a serem inventadas. Inventadas nesse diálogo, em que as novas tecnologias são apropriadas e recriadas pelo coletivo que as recebe tendo em vista sua experiência, ou, na linguagem da ergologia, pelo corpo-si como sede da memória no trabalho.

7 Nesta mesma linha, os artigos que se seguem incitam a busca de caminhos inovadores, de tomar o trabalho, aí incluído o trabalho do pensamento, da pesquisa acadêmica, da produção de conhecimento como desafio permanente.

8 O tema da saúde do trabalhador é abordado direta ou indiretamente em todos ou quase todos os capítulos. Destaco, neste tema, o artigo de Jussara Brito, militante ativa no campo da pesquisa e intervenção em saúde do trabalhador no Brasil Seu artigo traz a cena não apenas conceitos da ergologia, mas convergências que a autora identifica entre os caminhos propostos por esta corrente e as práticas desenvolvidas por e entre brasileiros. Prática ainda nova, desenvolvida especialmente nos últimos 20 anos e sempre chamada a enfrentar conflitos e desafios, demanda recursos que possam ser usados pelos trabalhadores que nela militam. Em especial, a autora comenta um autor que me é caro, que é Ivar Oddone. Este, por suas propostas ético-políticas, mais que por suas formulações teóricas, vem suscitando derivas interessantes nas produções da psicologia do trabalho.

9 Se, inspirados pela leitura, pensamos a aventura vivida pelos pesquisadores, psicólogos do trabalho, lingüistas, intelectuais e autores de diversas ordens, podemos pensar que "debate" o coletivo-autor e cada um dos autores deste livro provoca. Pensar o que se cria e o que se instiga neste movimento. O livro traz ao cenário brasileiro da Psicologia do Trabalho e da Saúde do Trabalhador temas, linhas de pensamento e autores que muito podem contribuir para o desenvolvimento destes campos e suas intercessões com outros campos que incluem em sua caixa de ferramentas os conceitos de trabalho e de atividade. Traz o objetivo comum a todos os autores/artigos de compreender o trabalho 
para transformá-lo, avançando de modo explícito em alguns para uma outra formulação: a de transformar o trabalho para compreendê-lo. Sendo o trabalho abordado pela via da atividade, e sendo a atividade conflito, diálogo e movimento sempre inacabado, é este processo de transformação permanente que se quer apreender. É nele que se quer intervir.

O livro é composto por 13 capítulos, organizados por seus atores em 4 partes.

11 Na primeira parte, "Ergologia : trabalho e gestão", o primeiro capítulo é, com foi dito acima, escrito por Yves Schwartz. Neste estão expostas algumas formulações importantes da ergologia, munindo o leitor de instrumentos que facilitarão sua aventura ao longo do livro. Neste artigo vale a pena ressaltar a visão de gestão que Schwartz nos traz, que se diferencia de administração, de gerenciamento do trabalho dos outros. Na concepção apresentada gestão é entendida como atividade de todos e de cada um, implicando valores, decisões, e modos de fazer frente. à variabilidade sempre presente. 0 capítulo brinda o leitor com o acesso às idéias de um autor instigante, ainda pouco publicado em língua portuguesa. E, ao menos no Brasil, a publicação em português por editora nacional, amplia consideravelmente o acesso.

12 A segunda parte, intitulada "Articulando conceitos e campos de conhecimento", nos apresenta produções no campo da ergonomia, saúde do trabalhador e lingüística, sempre buscando o diálogo com a abordagem ergológica. Inicia-se com o artigo de Abdallah Nouroudine, já comentado. Segue-se o artigo de Ana Luiza Telles e Denise Alvarez, que apresentam seus trabalhos de análise de duas atividades desenvolvidas no Brasil : a atenção no campo da Saúde Mental e o trabalho docente numa universidade pública. Jussara Brito, como foi dito acima, trata das convergências entre a saúde do trabalhador e a ergologia. A seguir, Maristela França discute a contribuição dada pela lingüística, em particular pela corrente dialógica, aos estudos de atividade humana industriosa.

13 A terceira parte busca "Afinidades metodológicas" entre a abordagem ergológica e outras três abordagens : a ergonomia situada, a psicologia do trabalho voltada para o desenvolvimento da atividade e a lingüística de Baktin e outros da dita lingüística aplicada. Encontramos nessa parte afinidades não apenas entre abordagens, mas entre autores. Catherine Teiger, Antoine Laville, Jacques Duraffourg e outros colegas nos apresentam um artigo de autoria coletiva, em que discutem ergonomia e ação sindical na França. Ricardo Vasconcelos e Marianne Lacomblez trazem uma discussão em que usam contribuições de Yves Clot. E Marcos Antonio Vieira nos traz um artigo em que aborda os dispositivos de autoconfrontação, trazendo então contribuições de autores como Ivar Oddone, Daniel Faïta, Yves Clot e Lívia Scheller.

14 E a quarta parte nos brinda com os relatos de trabalhos empíricos, sendo intitulada "Análise do trabalho: exercícios pluridisciplinares". São trabalhos de pesquisadores brasileiros, desenvolvidos no Brasil. Marcelo Figueiredo e Milton Athayde apresentam e discutem um estudo da atividade de mergulho em águas profundas na Bacia de Campos. Vera Sant'Anna, Maria Del Carmen Daher, Décio Rocha, Luise Campos da Silva, Maria Cristina Giogi e Paulo Carvalho Jr. estudam as lutas sindicais no ABC paulista. Mary Yale Neves, Milton Athayde e Helder Muniz nos relatam uma pesquisa com professoras na rede pública de ensino fundamental na Paraíba, nordeste do Brasil. E Helder Muniz, Mario César Vidal e Sarita Vieira discutem a atividade de enfermeiras em um hospital público universitário. 
Os trabalhos empíricos apresentados são produzidos no contexto acadêmico. Três deles estão relacionados às dissertações e teses de mestrado e doutorado de seus autores. $\mathrm{E}$ um é produzido por um laboratório acadêmico de pesquisa. Como dizem Ana Luiza Telles e Denise Alvarez (capítulo 3), não há no Brasil, ainda, uma demanda expressiva por intervenções no processo de trabalho, em especial aquelas que escapem a abordagens quantitativas apoiadas em medidas e na análise exclusiva dos aspectos técnicos e posturais. Estes são então trabalhos em que a demanda vem dos pesquisadores, vinculados a universidades e/ou centros de pesquisa e pós-graduação que ofertam sua cooperação aos trabalhadores. Creio que há aí uma importância a mais na realização e divulgação destas pesquisas-intervenções. Estas trazem a possibilidade de produção de demanda de análise e transformação, bem como de produção de demanda por formação no ofício de analista do trabalho por uma abordagem centrada na atividade. E certamente alimentarão novas práticas nas intervenções sobre os processos e ambientes de trabalho.

$16 \mathrm{Na}$ atividade daqueles que se dedicam a pesquisar-intervir no plano do trabalho são necessárias alianças, solidariedades, como de resto em todas as atividades humanas. Temos então no livro Labirintos do Trabalho uma ferramenta valiosa na gestão pertinente a esse cotidiano.

\section{AUTOR}

\section{CLÁUDIA OSÓRIO}

Professora do Departamento de Psicologia e do Mestrado em Psicologia Estudos da Subjectividade Universidade Federal Fluminense

Doutora em Saúde Púbica pela ENSP/Fiocruz 